\title{
Long-term outcome and quality of life after CNS cavernoma resection: eloquent vs. non-eloquent areas
}

\author{
Loay Shoubash $^{1}$ (D) Jörg Baldauf ${ }^{1} \cdot$ Marc Matthes $^{1} \cdot$ Michael Kirsch $^{2} \cdot$ Matthias Rath $^{3} \cdot$ Ute Felbor $^{3}$. \\ Henry W. S. Schroeder ${ }^{1}$
}

Received: 28 January 2021 / Revised: 18 April 2021 / Accepted: 26 May 2021 / Published online: 23 June 2021

(c) The Author(s) 2021

\begin{abstract}
The aim of this study is to analyze the long-term quality of life after surgery of cavernoma. A monocentric retrospective study was conducted on 69 patients with cavernoma treated microsurgically between 2000 and 2016 . The eloquence was adopted from Spetzler-Martin definition. A most recent follow-up was elicited between 2017 and 2019, in which the quality of life (QoL) was evaluated with the Short Form-12 questionnaire (SF12). Forty-one lesions were in eloquent group (EG), 22 in non-eloquent group (NEG), 3 in orbit, and 3 in the spinal cord. Postoperative worsening of the modified Rankin scale (mRS) occurred in 19.5\% of cases in EG versus 4.5\% in NEG. After a mean follow-up of 6.5 years (SD 4.6), the neurological status was better or unchanged compared to baseline in $85.4 \%$ of EG and $100 \%$ of NEG. Regarding QoL assessment of 44 patients (EG $n=27$, NEG $n=14$ ) attended the last follow-up. Patients after eloquent cavernoma resection reported a non-inferior QoL in most SF12 domains (except for physical role) compared to NEG. However, they reported general health perception inferior to norms, which was affected by the limited physical and emotional roles. At a late follow-up, the surgical morbidity was transient in the NEG and mostly recovered in the EG. The QoL comparison between eloquent and non-eloquent cavernomas created interesting and new data after prolonged follow-up. These results add value for decisionmaking as well as patient counseling for future encountered cases. Preoperative evaluation of QoL is recommended for future studies to assess QoL dynamics.
\end{abstract}

Keywords Cavernoma $\cdot$ Cavernous malformation $\cdot$ Eloquent area $\cdot$ Quality of life $\cdot$ Surgical resection $\cdot$ Neurological outcome

\section{Introduction}

Cavernoma or cavernous malformation (CM) is a benign non-shunting vascular malformation that is prone to bleed [25]. They account for $5-15 \%$ of the central nervous system (CNS) vascular malformations [10] and present with

Loay Shoubash

loay.shoubash@uni-greifswald.de

1 Department of Neurosurgery, University Medicine Greifswald, Ferdinand-Sauerbruch-Strasse, 17475 Greifswald, Germany

2 Department of Neuroradiology, University Medicine Greifswald, Greifswald, Germany

3 Department of Human Genetics, University Medicine Greifswald and Interfaculty Institute of Genetics and Functional Genomics, University of Greifswald, Greifswald, Germany seizures, focal neurologic deficits (FND), or incidentally [19]. Disease prevalence ranges from 0.4 to $0.8 \%$ [4, 13, 23]. The overall annual bleeding risk is $2.4 \%$ patient/year [12]. In previously unruptured $\mathrm{CM}$, the bleeding risk is $0.3-2.8 \%$ patient/year, but the risk reaches $6.3-32.2 \%$ patient/year once the cavernoma bled [2, 31].

In asymptomatic cavernomas, a "wait and see" conservative management could be the first choice $[16,20]$. Previous publications reported, however, that a bad preoperative performance level at the presentation is a predictive factor of a poor outcome. That means, "wait and see" strategy for eloquent CM after the first hemorrhage will leave these patients at risk of neurological deterioration from substantial bleedings, therefore decreasing the chance for complete recovery after surgery $[5,6,8]$. Given the increased risk of rehemorrhage, microsurgical resection remains the definitive treatment for CNS cavernomas [11]. 
The main concern is the outcome of surgical treatment. There is a need to validate the quality of life of the patients after surgical resection of the cavernoma, especially in deep or eloquent areas. By reviewing the literature, we found many studies that assess the outcome after CNS cavernoma surgery and to a lesser extent after surgery of cavernomas located in eloquent regions [6, 14, 15, 24, 28, 30, 36, 39]. However studies that assess the QoL are still rare. Only four studies assess the quality of life of these patients, including three studies that evaluated brainstem cases only [7-9, 17].

We performed this study to investigate two main aspects: (1) the neurological outcome and (2) quality of life after CNS cavernoma resection.

\section{Methods}

\section{Participants and study design}

From January 2000 to December 2016, 74 patients with cavernoma treated surgically at the University Hospital Greifswald were evaluated in this retrospective clinical study. This study was approved by the Human Research Ethics committee of the University of Greifswald (Study ID: BB 031/18).

\section{Inclusion criteria and information gathered}

The inclusion criteria were a histopathological confirmation of CNS cavernoma and complete data sets of the patients. Five patients were excluded from the study. Two had no clear histopathological confirmation of $\mathrm{CM}$, and the remaining three patients were lost to follow-up, leaving a total of 69 subjects included in the study. Clinical charts, imaging studies, operation notes, and follow-up notes were reviewed.

Information regarding the patient's gender, mean age at the surgery, location of the lesion, signs and symptoms, duration of the complaint, medications including antiepileptic drugs (AED) past medical history, preoperative MRI findings (including location and size [maximum diameter] of CMs and Zabramski classification [37] associated developmental venous anomaly (DVA)), length of stay, and length of the operation were gathered. Genetic counseling was offered to patients with a positive family history of CMs and multiple cavernomas.

The neurological examination (alertness/consciousness, orientation, dizziness, headache, cranial nerve status, sensomotoric deficit, gait, epilepsy) was standardized pre-and postoperatively according to the modified Rankin Scale (mRS) [22]. Based on the mRS, patients who presented with debilitating seizures or headaches were given mRS 1 . In contrast, the presentation of simple non-disabling fit or chronic sporadic recurrent headaches that are controlled on medications considered mRS 0. Postoperative change of at least one grade of mRS was defined as better or worse. Table 1 shows the distribution of the patients according to $\mathrm{mRS}$. A mRS score $\leq 2$ was defined as a favorable outcome, where a mRS score $>2$ was related to an unfavorable outcome.

\section{Eloquence}

Eloquence was adopted from Spetzler-Martin definition [29]. The following CM locations were treated: sensorimotor $n=14$, basal ganglia $n=2$, language $n=8$, visual pathway $n=5$, deep cerebellar nuclei or cerebellar peduncles $n=4$, and brainstem $n=8$. Twenty-two cavernomas were found in non-eloquent areas. Three lesions were located in the orbit and 3 in the spinal cord. Eight patients had multiple cavernomas. Detailed localization is summarized in Table 2.

The patients were categorized into two groups: eloquent group (EG) and non-eloquent group (NGE). The orbital and spinal cord cavernomas were excluded from the subgroup statistics for a reasonable comparison between the EG and NEG.
Table 1 Modified Rankin Scale demonstrates the corresponding results from the study

\begin{tabular}{lllllll}
\hline mRS [22] & $\begin{array}{l}\text { At presentation: } \\
\text { EG }\end{array}$ & NEG & $\begin{array}{l}\text { Directly postop: } \\
\text { EG }\end{array}$ & NEG & $\begin{array}{l}\text { Late follow-up: } \\
\text { EG }\end{array}$ & NEG \\
\hline 0 & 6 & 7 & 13 & 11 & 21 & 14 \\
1 & 23 & 14 & 16 & 9 & 9 & 7 \\
2 & 4 & 0 & 5 & 1 & 6 & 0 \\
3 & 3 & 0 & 4 & 0 & 1 & 0 \\
4 & 5 & 1 & 2 & 1 & 1 & 0 \\
5 & 0 & 0 & 1 & 0 & 3 & 0 \\
6 & 0 & 0 & 0 & 0 & 0 & $1+$ \\
\hline
\end{tabular}

$E G$ eloquent group; $m R S$ modified Rankin scale; $N E G$ non-eloquent group: postop postoperatively

\# some patients had a transient FND, and they had mRS 0 at the presentation

+ died from another disease 
Table 2 Anatomical and functional location distribution of the surgically resected $\mathrm{CM}$

\begin{tabular}{llll}
\hline Anatomical location distribution & & \multicolumn{2}{l}{ Functional location distribution } \\
\cline { 4 - 5 } No. of patients & & & No. of patients \\
\hline Frontal & 47 & Eloquent [29] & 41 \\
Temporal & 18 & Sensomotoric region & 14 \\
Parietal & 13 & Language & 8 \\
Parietooccipital & 7 & Visual & 5 \\
Occipital & 5 & Basal ganglia & 2 \\
& 2 & Cerebellum deep nuclei, and & 4 \\
Basal ganglia & 2 & peduncles & \\
Cerebellar & 8 & Brainstem & 8 \\
Brainstem & 8 & Non-Eloquent & 22 \\
Midbrain & 1 & Frontal & 7 \\
Pons & 4 & Temporal & 8 \\
Ponto-medullary & 1 & Parietal & 3 \\
Medulla oblongata & 2 & Cerebellar hemisphere & 4 \\
\hline
\end{tabular}

Others: spinal cord $n=3$, orbital $n=3$, multiple $n=8$

${ }^{*}$ all occipital lesions were in the visual eloquence

\section{Imaging protocols}

Brain MRI was routinely performed within one week before surgery, mostly for neuronavigation purposes. A standard presurgical workup was made, including functional MRI, neurophysiology testing, and epilepsy work-up when needed. Postoperative MRI was done within the first 3 months, then yearly, or at the last follow-up. The imaging studies were read by a neuroradiologist (MK).

Postoperative bleeding was defined as an extension of the bleeding outside the resection bed in the postoperative imaging studies.

\section{Surgical strategy}

The patients were operated on in our institute by different neurosurgeons. The aim of the surgery was a total lesionectomy. The treatment approach was harmonious in all cases. Different microsurgical approaches were selected depending on the case. A combination of intraoperative neuronavigation, ultrasound, awake surgery, or neurophysiologic monitoring was used as needed.

\section{Last follow-up}

The patients were invited for a follow-up, so-called last follow-up, in which 44 patients of the present study population could attend, and they were distributed as follows: EG $n=27, \mathrm{NEG}=14$, orbital $n=2$, spinal cord $n=1$. These patients were interviewed between 2017 and 2019.

In this follow-up, neurological status with an updated MRI was reviewed. The individuals were then asked to answer validated questionnaires of Quality of Life (QoL) of Short-Form 12 (SF12) [32], overall satisfaction, and reemployment status.

\section{Quality of life via Short-Form 12 (SF12)}

The overall respondents' rate of the SF12 questionnaire was $63.8 \%$ (44 out of 69 ). The mean interval between the surgery and the survey was 8.7 years.

SF12 survey contains 8 domains: (1) general health perceptions (GH general health); (2) limitations in usual role activities due to physical problems (RF functional role); (3) bodily pain(BP); (4) physical activities limitations due to health problems (PF physical functioning); (5) energy and fatigue (VT vitality); (6) limitations in social activities due to physical and emotional problems (SF social functioning); (7) limitations in usual role activities because of emotional problems (RE emotional role); and (8) general mental health, psychological distress and well-being (MH mental health).

The first 4 domains represent physical health and the last 4 represent mental health. The sum of each 4 domains generates a global score; physical composite scale (PCS) and mental health composite scale (MCS).

The sum of the questions in each of these 8 sections and the 2 global scores are transformed into a 0 to 100 scale. A lower score $(0)$ represents more disability, whereas a higher score means less disability, and 100 points equivalent to no disability. Results from this test were re-calculated as described in SF-12 Health Survey Manual [32] and compared to normative data from the general German population [35]. 
The evaluation of these results focused on a comparison between (1) the two groups EG and NEG and (2) the study population, EG, and NEG with a normative German population, respectively [35].

\section{Statistical analysis}

All data were expressed as mean and standard deviation. For subgroup analysis, Fisher's exact test was used for categorical variables. An independent two-sample t-test was performed for continuous variables. Both were used for the presentation of quantitative differences among subgroups. Additionally multivariate ANOVA was done to assess the difference in subgroups in regards to outcome related to mRS using STATA 13 (StataCorp. 2013. Stata Statistical Software: Release 13. College Station, TX: StataCorp LP.). Statistical analyses for the QoL were performed using commercially available software (SPSS, Ver. 20.0, IBM Corp., Armonk, New York, USA). Two-tailed $P$ value $<0.05$ was considered significant, and $P<0.01$ as highly significant.

\section{Results}

\section{Demographic data and clinical presentation}

Sixty-nine patients made up the study cohort, including 30 women (43.48\%) and 39 men (56.52\%). The average age at surgery was 41.3 years (SD 16.2, range 16-78 years). Table 3 demonstrates a summary of the demographic and clinical characteristics of the whole study population, EG, and NEG.

Among these patients, $29(42.0 \%)$ presented with FND, $24(34.8 \%)$ with symptomatic focal epilepsy, and 8 patients (11.6\%) with both FND and seizures.

Four patients $(5.8 \%)$ presented only with long-standing nonspecific headaches, and in $4(5.80 \%)$ patients the cavernoma was an incidental finding, where 2 of them presented because of remote bleeding and the other 2 due to non-cavernoma-related epilepsy.

The mean duration of preoperative clinical history was 40.2 months (SD 80.9) of all cavernomas. The mean last available follow-up was 6.5 years (SD 4.6).

Table 3 Demographic and clinical characteristics of 69 patients with CM divided into two groups: eloquent group (EG) and non-eloquent group (NEG)

\begin{tabular}{|c|c|c|c|c|}
\hline No. of patients & Study population 69 & $\begin{array}{l}\text { Eloquent group } \\
41\end{array}$ & $\begin{array}{l}\text { Non-eloquent group } \\
22\end{array}$ & Significance \\
\hline $\begin{array}{l}\text { Mean age at the operation in years } \\
\text { Female }(\%)\end{array}$ & $\begin{array}{l}41.7(\text { SD } 16.2) \\
\text { (range, } 16-78 \text { years) } \\
30(43.5 \%)\end{array}$ & $\begin{array}{l}42.4(\text { SD } 16.6) \\
22(53.7 \%)\end{array}$ & $\begin{array}{l}40.0(\text { SD 16.2) } \\
7(31.8 \%)\end{array}$ & \\
\hline Mean duration of presentation in months & $\begin{array}{l}40.2(\mathrm{SD} 80.9) \\
\text { (range, } 1-400)\end{array}$ & $48.4(\mathrm{SD} 94,5)$ & $26.3(\mathrm{SD} 63.2)$ & \\
\hline \multicolumn{5}{|l|}{ Symptoms (\%) } \\
\hline - FND & $-29(42.0 \%)$ & $-19(46.3 \%)$ & $-4(18.1 \%)$ & \\
\hline - seizure & $-24(34.9 \%)$ & $-13(31.2 \%)$ & $-11(50.0 \%)$ & \\
\hline - FND and Seizure & $-8(11.6 \%)$ & $-6(14.6 \%)$ & $-2(9.1 \%)$ & \\
\hline - Incidental & $-4(5.8 \%)$ & $-1(2.4 \%)$ & $-3(13.6 \%)$ & \\
\hline - Headache & $-4(5.8 \%)$ & $-2(4.9 \%)$ & $-2(9.1 \%)$ & \\
\hline Mean follow-up in years & $\begin{array}{l}6.5(\mathrm{SD} 4.6) \\
\text { (range, 1-18) }\end{array}$ & $5.8(\mathrm{SD} 4.0)$ & $7.6(\mathrm{SD} 5.6)$ & \\
\hline Mean $\mathrm{CM}$ size in $\mathrm{mm}$ & $\begin{array}{l}\text { 18.1 (SD 10.4) } \\
\text { (range 4-56) }\end{array}$ & $18.4(\mathrm{SD} 9.8)$ & $16.1(\mathrm{SD} 9.0)$ & NS \\
\hline Mean operation time in minutes & $\begin{array}{l}223.0(\text { SD 100.0) } \\
\text { (range, 82-573) }\end{array}$ & $240.2(\mathrm{SD} 100.1)$ & $184.6(\mathrm{SD} 94.6)$ & $P$-Value $=0.0362 \dagger$ \\
\hline Mean length of stay in days & $\begin{array}{l}9.9(\mathrm{SD} 4.3) \\
\text { (range, 5-28) }\end{array}$ & $10.2(\mathrm{SD} 4.9)$ & $9.5(\mathrm{SD} 3.4)$ & NS \\
\hline \multicolumn{5}{|l|}{ Zabramski class [37] } \\
\hline I/II/III/IV & $22 / 40 / 7 / 0$ & $13 / 27 / 1 / 0$ & $5 / 11 / 6 / 0$ & \\
\hline Rate $(\%)$ & $32 / 58 / 10 / 0$ & $32 / 66 / 2$ & $23 / 50 / 27 / 0$ & \\
\hline
\end{tabular}

$C M$ cavernous malformation; $F N D$ focal neurological deficit; $N S$ non-significant; $S D$ standard deviation

Values represent numbers of cases (\%) unless otherwise indicated. Mean values are presented with standard deviations. p values are for comparison of the difference between subgroups 


\section{Genetic profiles}

Since a positive family history and multiple CMs are indicative of the familial form of CCM, genetic counseling was offered to all study participants who met these criteria. Three of the eight patients gave their written informed consent for genetic analyses of the three disease-associated genes $C C M 1$ (also known as KRIT1), CCM2, and CCM3 (also known as $P D C D 10$ ). A pathogenic $C C M 1$ frameshift variant was identified in one patient, and a $C C M 2$ splice site mutation, which was also classified as pathogenic, according to the American College of Medical Genetics and Genomics (ACMG) guidelines [26], was detected in two brothers. [21]

\section{Imaging and surgical outcome}

The most common type of MRI presentation was type 2 Zabramski grade (58.0\%).

Complete resection was achieved in 67 patients (97.1\%) determined by intraoperative inspection and postoperative MR imaging. An accompanying DVA was detected in 19 patients (27.5\%) and was preserved in all cases (Fig. 1).
The duration of the operation in EG was longer than for the NEG; the difference was significant ( $P=0.0362$, t-test).

\section{Complications and surgical morbidity}

Directly postoperatively, new FND or worsening of the presenting symptoms, as noted in Table 4, was observed in $31.7 \%$ of the EG and $4.5 \%$ of the NEG. An immediate worsening of one or more grades on the mRS was seen in 19.5\% of patients with eloquent cavernomas and $4.5 \%$ of patients with non-eloquent cavernomas corresponding to the surgical morbidity. There were no cases of mortality.

At the late follow-up, after a mean follow-up time of 6.5 years, the status was equal or better than the baseline at presentation in $85.4 \%$ of patients in the EG vs $100 \%$ in the NEG. (Fig. 2).

An unfavorable outcome (mRS > 2) was seen in $12.2 \%$ of patients in EG and 0\% in NEG at the last follow-up. The change of mRS throughout the course of the disease is illustrated in (Fig. 3). A statistically non-significant improvement of neurological deficit (mRS) was observed in both groups between the preoperative presentation and
Fig. $1 \mathrm{CM}$ in the left middle cerebellar peduncle. Preoperative axial (a) and coronal (b) T1-weighted images with gadolinium demonstrating cavernoma with associated DVA. Postoperative axial (c) and coronal (d) T1-weighted images with gadolinium, showing complete resection of the CM with preservation of the DVA
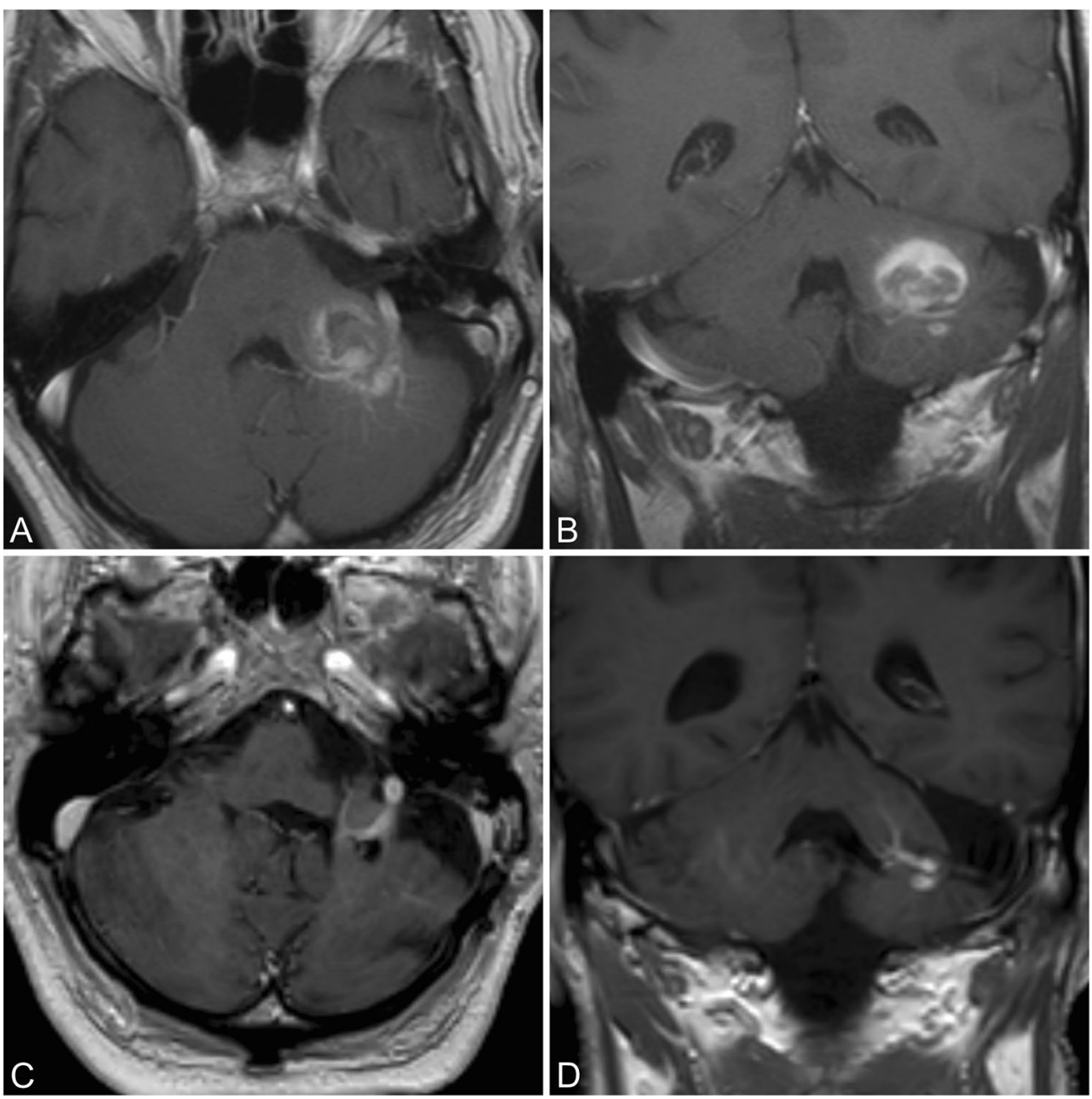
Table 4 List of the postoperative complications

\begin{tabular}{lll}
\hline & No & Comments: \\
\hline FND & 5 & Some patients had mixed \\
-Paresis & 4 & FND \\
-Paresthesia & 1 & \\
-Dysphasia & 1 & \\
-Cognitive dysfunction & 2 & \\
-Ataxia & 3 & \\
-Diplopia & 1 & \\
-Visual field defect & 4 & \\
Postoperative bleeding\# & & \\
Medical problem & 1 & \\
Deep vein thrombosis & 1 & PE occurred in a patient with \\
Pulmonary embolism & & brainstem cavernoma \\
& 1 & 1 reoperation \\
Wound infection & 2 & 1 reoperation \\
CSF Fistula &
\end{tabular}

\# bleeding that slightly extended from the resection bed in the postoperative imaging

CSF cerebrospinal fluids; $C R E$ cavernoma related epilepsy; FND focal neurological deficit; $P E$ pulmonary embolism long-term follow-up; NEG improvement of -0.11 on the $\mathrm{mRS}(p=0.496)$ vs EG improvement of -0.17 on the mRS $(p=0.265)$.

Twelve out of 63 patients (19.0\%) who presented with intracranial CM had preoperatively chronic disabling headaches. At the last follow-up, only one patient (1.6\%) had persisting headache episodes.

\section{Rebleeding and reoperation}

Postoperative bleeding was detected in the routine postoperative brain image in 4 patients $(5.7 \%)$ without any clinical manifestation. None of them required surgical evacuation.

As demonstrated in Table 4, two postoperative complications necessitated a reoperation, due to CSF fistula, and postoperative wound infection.

\section{Epilepsy outcome and antiepileptic drugs (AED)}

Regarding cavernoma-related epilepsy, 23 out of 29 patients (79.3\%) reported seizure-free or only rarely disabling seizures after surgery (Engel classification 1) [34], while 31.0\%
Fig. 2 Pontine CM. Preoperative axial T2-weighted image (a) and axial gradient echo image (b). Postoperative axial T2-weighted image (c) and axial T1-weighted image (d). The patient presented with mixed neurological deficits with mRS 2 at the presentation that was better at the follow-up and reported an overall favorable quality of life

Fig. 3 Difference between the eloquent group and noneloquent group according to mRS over the course of the disease. The $\mathrm{p}$ values depicted in the diagram indicate the difference between both groups for each time point of evaluation. $\mathrm{mRS}=$ modified Rankin scale; preop = preoperative; postop $=$ postoperative; long term $=$ at the last follow-up 6.5 years \pm 4.6 (range, $1-18$ )

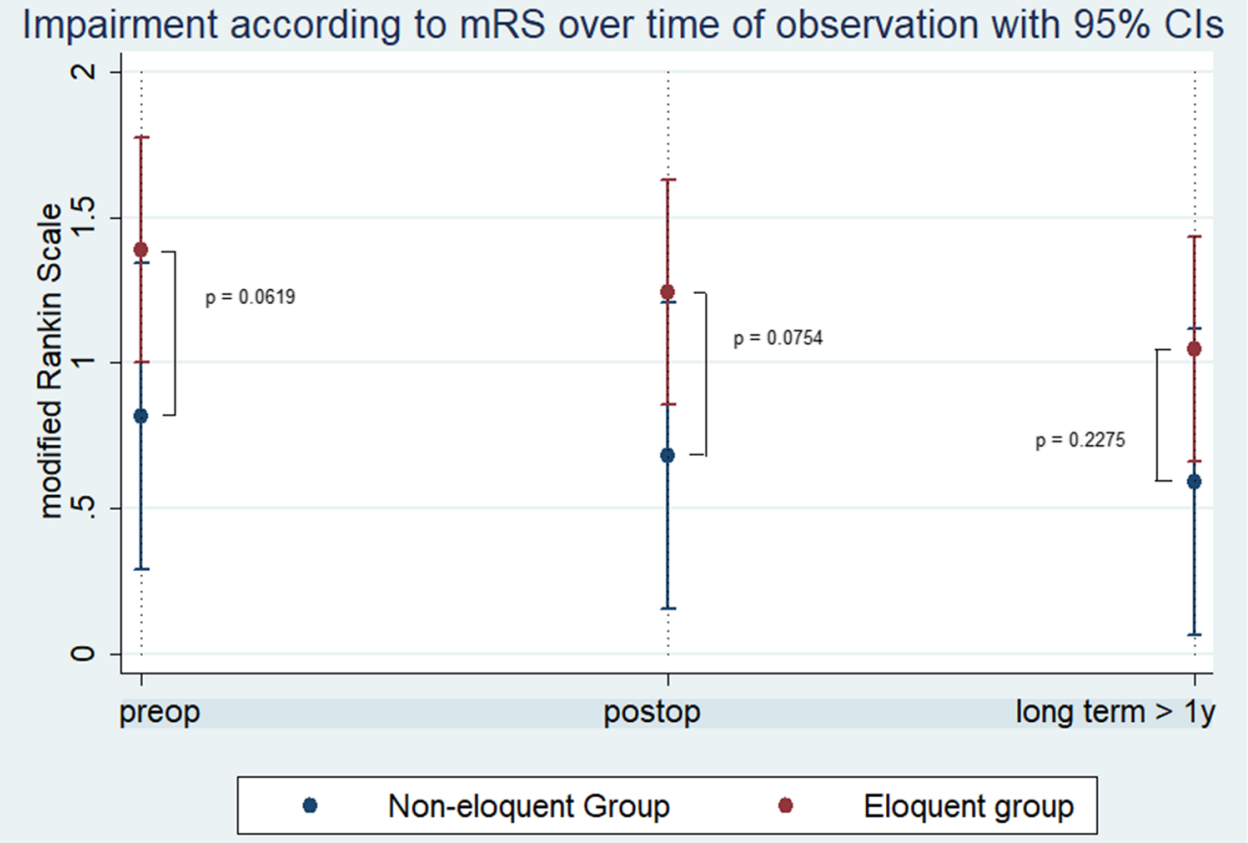

of the patients were able to discontinue the AED and 17.2\% of patients could decrease at least one AED.

\section{Return to work and patient satisfaction}

In response to the supplementary question at the last follow-up ( $n=44)$ ("Did the operation meet your expectations about the postoperative course of the treatment"), $88.8 \%$ of the patients expressed their satisfaction with the treatment, while $11.2 \%$ found that the surgical treatment did not meet their expectations.

Regarding reemployment or return to baseline activity, 16 out of 27 -asked patients $(59.3 \%)$ in the EG were able to return to work compared to $12 / 14$ patients $(85.7 \%)$ in the NEG, including two retired patients that were able to do the housework as before the operation. This difference between the two groups was not significant.

\section{Health-related quality of life (QoL)}

The assessment of QoL with the SF12 questionnaire was performed during the last follow-up. The overall respondents' rate of the SF12 questionnaire was 44 cases $(63.8 \%)$. The mean interval between the surgery and the survey was 8.7 years.

The results are demonstrated in Table 5 and illustrated in Fig. 4.

1) QoL according to eloquence, EG vs. NEG: the subgroup analysis showed no statistical difference between both subgroups after a long follow-up. The EG showed a slightly better score in general health $(\mathrm{GH})$ and bodily pain (BP) domains, where the physical role (RP) was more limited in the EG.

2) Comparison with the normative German population (norms): The physical and mental component score of the entire study population and the subgroups when compared with norms showed no statistically significant difference. The patients scored equal to the norms regarding the mental component score.

Regarding physical health analysis; the general health $(\mathrm{GH})$ was significantly better in norms compared to subgroups.

The physical role (RP) also showed a better score in norms; this difference was significant compared to EG and the study population ( $p<0.05$, t-test), but not to the NEG.

In mental health analysis; the patients reported vitality (VT, energy level) and emotional role (RE) perception significantly inferior to the normative population as Table 5 illustrated.

\section{Discussion}

\section{Neurosurgical outcome}

In this study, $94.1 \%$ of patients were symptomatic, $88.4 \%$ of the patients presented with new neurological symptoms before surgery. Short-term morbidity after surgery was seen 
Table 5 Results of SF-12 questionnaire for study population, subgroups, and healthy population (Germany) [35]

\begin{tabular}{|c|c|c|c|c|c|c|c|c|}
\hline & $\begin{array}{l}\text { Study n44* } \\
\text { Mean (SD) }\end{array}$ & $\begin{array}{l}\text { German } \\
\text { population } \\
n 2524 \\
\text { Mean (SD) }\end{array}$ & Study vs norms & $\begin{array}{l}\text { EG } \\
n 27 \\
\text { Mean (SD) }\end{array}$ & $\begin{array}{l}\text { NEG } \\
n 14 \\
\text { Mean (SD) }\end{array}$ & EG vs norms & NEG vs norm & EG vs NEG \\
\hline $\mathrm{GH}$ & $\begin{array}{l}42.73 \\
(27.05)\end{array}$ & $\begin{array}{l}59.79 \\
(23.10)\end{array}$ & $\begin{array}{l}P<0.0001 \\
\text { t-test }\end{array}$ & $\begin{array}{l}47.59 \\
(26.36)\end{array}$ & $\begin{array}{l}38.93 \\
(27.89)\end{array}$ & $\begin{array}{l}P=0.0064 \\
\text { t-test }\end{array}$ & $P=0.0007 \mathrm{t}$-test & NS \\
\hline $\mathrm{PF}$ & $\begin{array}{l}85.80 \\
(27.70)\end{array}$ & $\begin{array}{l}86.76 \\
(24.32)\end{array}$ & NS & $\begin{array}{l}85.19 \\
(27.09)\end{array}$ & $\begin{array}{l}82.14 \\
(30.11)\end{array}$ & NS & NS & NS \\
\hline $\mathrm{RP}$ & $\begin{array}{l}75.85 \\
(27.41)\end{array}$ & $\begin{array}{l}83.61 \\
(22.55)\end{array}$ & $\begin{array}{l}P=0.0243 \\
\text { t-test }\end{array}$ & $\begin{array}{l}73.61 \\
(30.29)\end{array}$ & $\begin{array}{l}76.79 \\
(23.95)\end{array}$ & $\begin{array}{l}P=0.0225 \\
\text { T-Test }\end{array}$ & NS & NS \\
\hline $\mathrm{BP}$ & $\begin{array}{l}85.80 \\
(21.16)\end{array}$ & $\begin{array}{l}85.66 \\
(23.15)\end{array}$ & NS & $\begin{array}{l}87.96 \\
(17.50)\end{array}$ & $\begin{array}{l}78.57 \\
(27.49)\end{array}$ & NS & NS & NS \\
\hline VT & $\begin{array}{l}63.64 \\
(22.53)\end{array}$ & $\begin{array}{l}70.40 \\
(18.56)\end{array}$ & $\begin{array}{l}P=0.0171 \\
\text { t-test }\end{array}$ & $\begin{array}{l}63.89 \\
(25.32)\end{array}$ & $\begin{array}{l}60.71 \\
(18.90)\end{array}$ & NS & NS & NS \\
\hline SF & $\begin{array}{l}85.23 \\
(23.08)\end{array}$ & $\begin{array}{l}87.83 \\
(20.10)\end{array}$ & NS & $\begin{array}{l}86.11 \\
(21.18)\end{array}$ & $\begin{array}{l}82.14 \\
(28.47)\end{array}$ & NS & NS & NS \\
\hline $\mathrm{RE}$ & $\begin{array}{l}77.27 \\
(26.72)\end{array}$ & $\begin{array}{l}87.51 \\
(20.45)\end{array}$ & $\begin{array}{l}P=0.0011 \\
\mathrm{t} \text {-test }\end{array}$ & $\begin{array}{l}76.85 \\
(27.89)\end{array}$ & $\begin{array}{l}75.89 \\
(27.50)\end{array}$ & $\begin{array}{l}P=0.0073 \\
\text { t-test }\end{array}$ & $\begin{array}{l}P=0.0344 \\
\text { t-test }\end{array}$ & NS \\
\hline MH & $\begin{array}{l}74.72 \\
(16.06)\end{array}$ & $\begin{array}{l}80.10 \\
(22.73)\end{array}$ & NS & $\begin{array}{l}76.85 \\
(17.92)\end{array}$ & $\begin{array}{l}73.21 \\
(11.87)\end{array}$ & NS & NS & NS \\
\hline PCS & $\begin{array}{l}47.81 \\
(6.00)\end{array}$ & $\begin{array}{l}50.00 \\
(10.12)\end{array}$ & NS & $\begin{array}{l}48.04 \\
(5.97)\end{array}$ & $\begin{array}{l}46.31 \\
(5.97)\end{array}$ & NS & NS & NS \\
\hline MCS & $\begin{array}{l}50.11 \\
(9.12)\end{array}$ & $\begin{array}{l}49.99 \\
(10.08)\end{array}$ & NS & $\begin{array}{l}50.69 \\
(9.61)\end{array}$ & $\begin{array}{l}49.43 \\
(9.12)\end{array}$ & NS & NS & NS \\
\hline
\end{tabular}

${ }^{*} n=44$ divided in EG $n=27, \mathrm{NEG}=14$, orbital $n=2$, and spinal cord $n=1$

$B P$ bodily pain; $E G$ eloquent group; $G H$ general health perceptions; $M C S$ mental health composite scale; $M H$ mental health; $N E G$ non-eloquent group; NS not significant; $P C S$ physical composite scale; $P F$ physical functioning; $R E$ role emotional; $R P$ role physical; $S F$ social functioning; $V T$ vitality

in $19.5 \%$ of cases in the EG versus $4.5 \%$ in the NEG. Longterm morbidity was in $14.6 \%$ of cases in the EG versus $0 \%$ in the NEG.

The results in the presented study were comparable to the outcome stated in the literature. A larger study $(n=79)$ reported $97.4 \%$ of the patients had better or identical status after supratentorial cavernoma resection in eloquent areas at last follow-up [6]. Wostrack et al. ( $n=41)$ reported $47 \%$ of patients had a new postoperative deficit. At follow-up, $80 \%$ recovered to at least preoperative status [36]. In a recent study by Sanmillan et al. that assessed the surgical outcome of 20 patients who presented with cavernoma in eloquent location, $50 \%$ of patients had transient deterioration that all recovered after 1 year [28].

Regarding brainstem cavernomas, $62.5 \%$ of our patients had a better or identical neurological outcome at the last follow-up. A study of a larger cohort of brainstem cavernomas $(n=260)$ showed a rate of new postoperative FND in $53 \%$ of the patients and permanent morbidity with new deficits remained in $36 \%$ of them after a mean follow-up of 51 months [1].

When left untreated, the eloquent lesions and especially brainstem lesions will deteriorate due to the increased rebleeding rate (estimated 6.3\% patient/year for non-brainstem and $32.2 \%$ patient/year for brainstem lesions that could also reach up to $52.7 \%$ patient/year) [31]. Knowing the natural history of eloquent cavernomas and to a lesser extent brainstem cavernomas justifies the decision of surgery in these eloquent areas [18, 27, 36].

The fear of surgical morbidity should be reconsidered when we look at the prolonged follow-up of the patients, where the neurological deficits will mostly recover and the risk of hemorrhage from the cavernoma will decrease or even be eliminated by the complete resection.

\section{Return to work}

The rate of patients returning to work in EG was lower than the NEG (59.3\% vs $85.7 \%$ ). Correlated to QoL and mRS results, the limiting physical role (RP) and unfavorable outcome (mRS $>2)$ at the last follow-up $(12.2 \%$ vs $0 \%$ as shown in Table 1) could contribute to the difference between the two groups. Other factors such as age, gender, and AED status did not show a correlation to this difference.

Our results from patients in the EG returned to work compared to a larger multicentric survey from Zanello et al. showed a lower proportion of patients returning to work (59.3\% vs $88.6 \%$, respectively) [38]. This difference between 


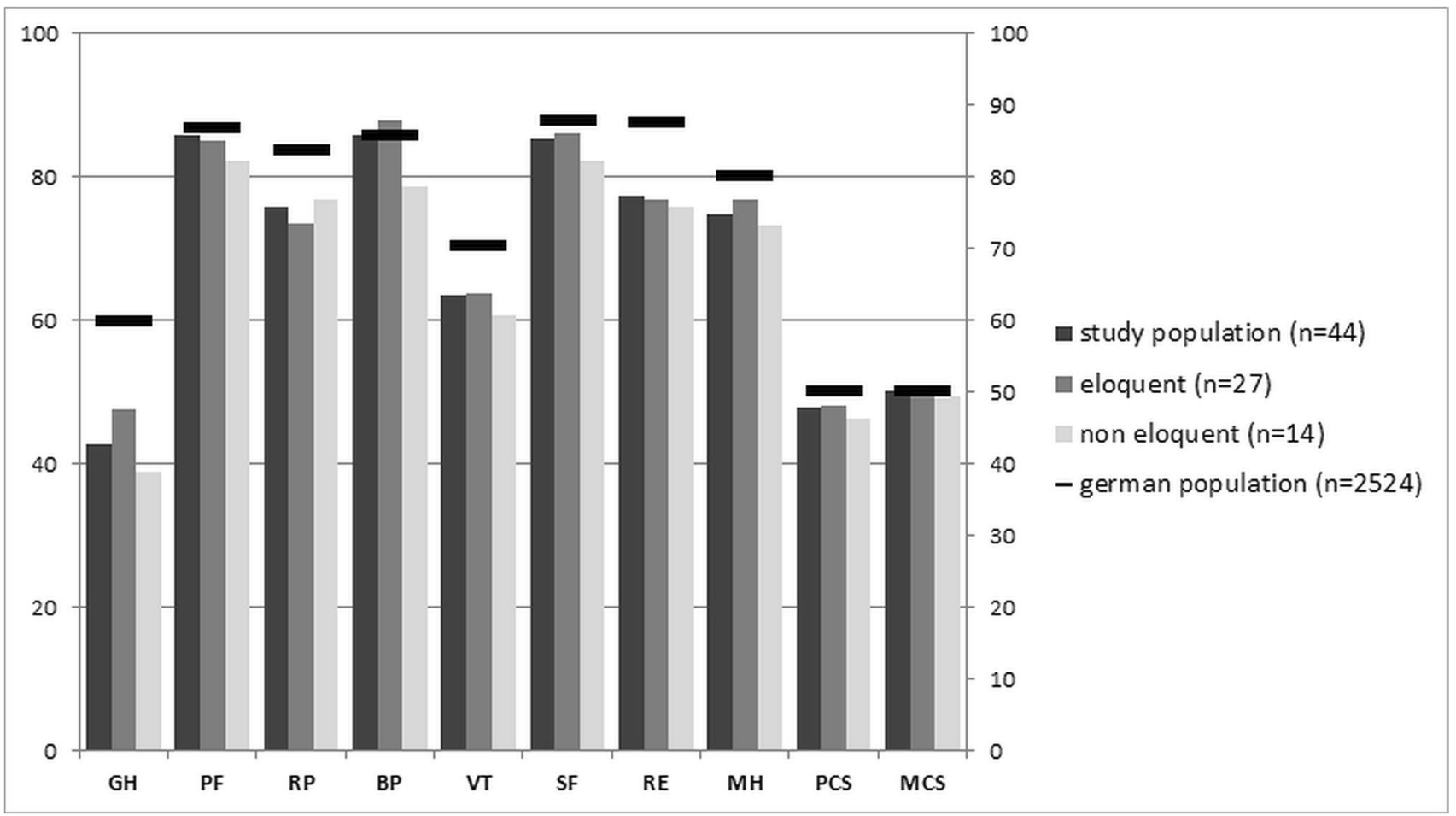

Fig. 4 Barograph displaying the results of SF12 questionnaire for the study population (black), eloquent subgroup (gray), non-eloquent subgroup (white), and healthy German population (black line). The 8 items and the 2 global scores of the questionnaire are presented on the $\mathrm{x}$-axis. The scale is from 0 to 100 demonstrated on the $y$-axis. The study population that made up the last follow-up $(n=44)$ was distrib-

our results and this survey is hard to explain since both studies lack a suppurative socioeconomic data of these patients. The mean age of both populations ( 42.4 vs. 40.2 years) as well as the slight female predominance (53.7\% vs $59.6 \%)$ and functional worsening at the follow-up (14.6\% vs $12.9 \%)$ were similar.

\section{Health-related quality of life}

The QoL of patients after cavernoma resection was assessed in four previous publications, including three studies for brainstem cavernomas only. Cornelius et al. compared the quality of life between the brainstem and non-brainstem cavernomas. They found, expectedly, that patients with a brainstem lesion were far more inferior regarding physical health domains of the QoL. Previous studies about QoL of patients after brainstem cavernoma surgery reported a favorable $\mathrm{QoL}$ in terms of mental health aspects [7, 9, 17].

Another study has been conducted considering patients' satisfaction with cavernoma-related epilepsy. The assessment, however, took part through a survey per mail [33].

The difference in this study is seen in the physical functioning $(\mathrm{PF})$ domain. Our patients reported a good score in uted as follows: eloquent group $n=27$, non-eloquent group $n=14$, orbital $n=2$, spinal cord $n=1$. $\mathrm{BP}=$ bodily pain; $\mathrm{GH}=$ general health perceptions; $\mathrm{MCS}=$ mental health composite scale; $\mathrm{MH}=$ mental health; $\mathrm{PCS}=$ physical composite scale; $\mathrm{PF}=$ physical functioning; $\mathrm{RE}=$ role emotional; $\mathrm{RP}=$ role physical; $\mathrm{SF}=$ social functioning; $\mathrm{VT}=$ vitality

this domain, in contrast to previous studies. Our explanation is as follows: the previous studies included brainstem cavernomas as a group and compared it with the normative population [7-9, 17], or with non-brainstem group [7]. Unsurprisingly, the brainstem group reported an inferior score regarding physical functioning. In the present study, patients in the eloquent group could have a visual field defect or mild hemiparesthesia and still report a good physical functioning perception compared to the brainstem group; this could explain the observed difference.

Furthermore, none of the studies mentioned above assessed the QoL of their study population sorted by functional location of the lesion (eloquence). They instead compared brainstem with non-brainstem cavernoma or normal population. The non-brainstem cavernomas have a wide range of presentations from asymptomatic to significant disability depending on the eloquence. The perception of QoL in patients with disabilities differs from patients with oligosymptomatic state. Moreover, some recommendations from the Angioma Alliance for cavernoma management from Akers et al. relied on the eloquence of the lesion [3]. Hence, the present study assesses the QoL distributed accordingly. 
To summarize the results about the QoL, we found that patients with cavernoma located in eloquent regions after surgery mostly had a non-inferior QoL compared to NEG except the physical role (RP) domain. Compared to their normative correspondence, the EG reported general health (GH) perception inferior to norms, which was related to limited physical and emotional roles.

Our results in line with the results of the previous studies show that the QoL accompanied by the neurological outcome is an essential and powerful element to support the decision for treating CNS cavernomas, especially if the cavernoma is in an eloquent area.

\section{Strength and limitation of the study}

A major strength of this study is that we conducted faceto-face interviews for QoL measurements in more than half of the patients in a prolonged period after surgery (mean time-to-interview 8.7 years). Some previous studies conducted such interviews via mail or telephone only $[7,9,33]$. Moreover, the correlation to the normal German population was from the same survey done in 2018 ; that time is comparable to the time of the follow-up of this study.

However, there are some limitations to our study. First, we only recruited participants from a single tertiary care center, and the results might not be generalized to other settings or populations. Second, this study is a retrospective study that lacks a randomized controlled group. Third, the sample size for the QoL assessment $(n=44)$ with a further subdivision of EG $(n=27)$ and NEG $(n=14)$ is relatively small. This could lead to poor statistical significance when testing the QoL domains between the two groups, EG and NEG.

Fourth, as the previously conducted studies about QoL of cavernoma patients, there was no preoperative QoL assessment or socioeconomic data of our patients to correlate the improvement of QoL postoperatively due to the retrospective design of the study.

In summary, the present study adds information to the literature about QoL after cavernoma surgery, which is needed to validate patients' well-being after surgical treatment. The comparison between eloquent and non-eloquent cavernomas, created interesting and new results after prolonged followup. The assessment of CNS Cavernoma QoL has only rarely been performed $[7-9,17]$.

\section{Conclusion}

At a late follow-up, the surgical morbidity was transient in the NEG and mostly recovered in the EG $(85.4 \%$ of patients). Regarding QoL, patients after eloquent cavernoma resection reported a non-inferior QoL in most SF12 domains (except for physical role RP) compared to NEG. However, they reported general health perception inferior to norms, which was affected by the limited physical and emotional roles. These results of how these patients are doing years after surgery could improve the decision-making as well as the patient counseling for future encountered cases of cavernomas in eloquent and non-eloquent regions. When reporting the neurosurgical outcome after CNS cavernoma resection, the QoL outcome is an essential measurement. For future studies, preoperative QoL measurements for the assessment of QoL dynamics are highly recommended.

Author contribution All authors (Mr. Loay Shoubash, Dr. Jörg Baldauf, Mr. Marc Matthes, Dr. Michael Kirsch, Dr. Matthias Rath, Prof. Ute Felbor, Prof. Henry W. S. Schroeder) contributed to the study conception and design. Material preparation, data collection, and analysis were performed by Mr. Loay Shoubash, Mr. Marc Matthes, and Dr. Matthias Rath. The first draft of the manuscript was written by Mr. Loay Shoubash, and all authors commented on previous versions of the manuscript. All authors read and approved the final manuscript.

Funding Open Access funding enabled and organized by Projekt DEAL.

Data availability Raw data were generated at University Medicine Greifswald. Derived data supporting the findings of this study are available from the corresponding author LS on request.

Code availability Not applicable.

\section{Declarations}

Ethics approval The questionnaire and methodology for this study were approved by the Human Research Ethics committee of the University of Greifswald (Study ID: BB 031/18).

Consent to participate This retrospective anonymized study did not require consent to participate from all individual participants. Informed consent was only obtained from the individuals that participated in the last elicited follow-up.

Consent for publication Not applicable.

Conflict of interest The authors declare no competing interests.

Open Access This article is licensed under a Creative Commons Attribution 4.0 International License, which permits use, sharing, adaptation, distribution and reproduction in any medium or format, as long as you give appropriate credit to the original author(s) and the source, provide a link to the Creative Commons licence, and indicate if changes were made. The images or other third party material in this article are included in the article's Creative Commons licence, unless indicated otherwise in a credit line to the material. If material is not included in the article's Creative Commons licence and your intended use is not permitted by statutory regulation or exceeds the permitted use, you will need to obtain permission directly from the copyright holder. To view a copy of this licence, visit http://creativecommons.org/licenses/by/4.0/. 


\section{References}

1. Abla AA, Lekovic GP, Turner JD, de Oliveira JG, Porter R, Spetzler RF (2011) Advances in the treatment and outcome of brainstem cavernous malformation surgery: a single-center case series of 300 surgically treated patients. Neurosurgery 68:403-14

2. Aiba T, Tanaka R, Koike T, Kameyama S, Takeda N, Komata T (1995) Natural history of intracranial cavernous malformations. J Neurosurg 83:56-59

3. Akers A, Al-Shahi Salman R, Awad IA, Dahlem K, Flemming K, Hart B, Kim H, Jusue-Torres I, Kondziolka D, Lee C, Morrison L, Rigamonti D, Rebeiz T, Tournier-Lasserve E, Waggoner D, Whitehead K (2017) Synopsis of guidelines for the clinical management of cerebral cavernous malformations: consensus recommendations based on systematic literature review by the Angioma Alliance Scientific Advisory Board Clinical Experts Panel. Neurosurgery 80:665-680

4. Al-Holou WN, O'Lynnger TM, Pandey AS, Gemmete JJ, Gregory Thompson B, Muraszko KM, Garton HJL, Maher CO (2012) Natural history and imaging prevalence of cavernous malformations in children and young adults. https://doi.org/10.3171/2011. 11.PEDS 11390

5. Bertalanffy H, Gilsbach JM, Eggert RH, Seeger W (1991) Microsurgery of deep-seated cavernous angiomas: Report of 26 cases. Acta Neurochirurgica 108:91-99

6. Chang EF, Gabriel RA, Potts MB, Berger MS, Lawton MT (2011) Supratentorial cavernous malformations in eloquent and deep locations: surgical approaches and outcomes. J Neurosurg 114:814-827

7. Cornelius JF, Kürten K, Fischer I, Hänggi D, Steiger HJ (2016) Quality of Life after surgery for cerebral cavernoma: brainstem versus nonbrainstem location. World Neurosurg 95:315-321

8. Dammann P, Herten A, Santos AN, Rauschenbach L, Chen B, Oppong MD, Schmidt B, Forsting M, Kleinschnitz C, Sure U (2020) Multimodal outcome assessment after surgery for brainstem cavernous malformations. https://doi.org/10.3171/2020.6.JNS201823

9. Dukatz T, Sarnthein J, Sitter H, Bozinov O, Benes L, Sure U, Bertalanffy H (2011) Quality of life after brainstem cavernoma surgery in 71 patients. Neurosurgery 69:689-695

10. Goldstein HE, Solomon RA (2017) Epidemiology of cavernous malformations. Handb Clin Neurol 143:241-247

11. Gross BA, Du R (2017) Hemorrhage from cerebral cavernous malformations: a systematic pooled analysis. J Neurosurg 126:1079-1087

12. Gross BA, Lin N, Du R, Day AL (2011) The natural history of intracranial cavernous malformations. Neurosurg Focus 30:E24

13. Horne MA, Flemming KD, Su I-C, Stapf C, Jeon JP, Li D, Maxwell SS, White P, Christianson TJ, Agid R, Cho W-S, Oh CW, Wu Z, Zhang J-T, Kim JE, Ter Brugge K, Willinsky R, Brown RD Jr, Murray GD, Al-Shahi Salman R, Cerebral cavernous malformations individual patient data meta-analysis collaborators (2016) Clinical course of untreated cerebral cavernous malformations: a meta-analysis of individual patient data. Lancet Neurol $15: 166-173$

14. Jung YJ, Hong SC, Seo DW, Hong SB (2006) Surgical resection of cavernous angiomas located in eloquent areas-clinical research. Acta Neurochir Suppl 99:103-108

15. Kivelev J, Koskela E, Setälä K, Niemelä M, Hernesniemi J (2012) Long-term visual outcome after microsurgical removal of occipital lobe cavernomas. J Neurosurg 117:295-301

16. Kupersmith MJ, Kalish H, Epstein F, Yu G, Berenstein A, Woo H, Jafar J, Mandel G, De Lara F (2001) Natural history of brainstem cavernous malformations. Neurosurgery 48:47-53

17. Lashkarivand A, Ringstad G, Eide PK (2019) Surgery for brainstem cavernous malformations: association between preoperative grade and postoperative quality of life. Oper Neurosurg (Hagerstown). https://doi.org/10.1093/ons/opz337

18. Mathiesen T, Edner G, Kihlström L (2003) Deep and brainstem cavernomas: a consecutive 8-year series. J Neurosurg 99:31-37

19. Morris Z, Whiteley WN, Longstreth WT Jr, Weber F, Lee Y-C, Tsushima Y, Alphs H, Ladd SC, Warlow C, Wardlaw JM, AlShahi Salman R (2009) Incidental findings on brain magnetic resonance imaging: systematic review and meta-analysis. BMJ 339:b3016

20. Mouchtouris N, Chalouhi N, Chitale A, Starke RM, Tjoumakaris SI, Rosenwasser RH, Jabbour PM (2015) Management of cerebral cavernous malformations: from diagnosis to treatment. Sci World J 2015.https://doi.org/10.1155/2015/808314

21. Much CD, Schwefel K, Skowronek D, Shoubash L, von Podewils F, Elbracht M, Spiegler S, Kurth I, Flöel A, Schroeder HWS, Felbor U, Rath M (2019) Novel pathogenic variants in a cassette exon of CCM2 in patients with cerebral cavernous malformations. Front Neurol 10:1219

22. New PW, Buchbinder R (2006) Critical appraisal and review of the Rankin scale and its derivatives. Neuroepidemiology 26:4-15

23. Otten P, Pizzolato GP, Rilliet B, Berney J (1989) 131 cases of cavernous angioma (cavernomas) of the CNS, discovered by retrospective analysis of 24,535 autopsies. Neurochirurgie 35(82-3):128-131

24 Pinsker M, Nabavi A, Mehdorn H (2007) Neuronavigation and resection of lesions located in eloquent brain areas under local anesthesia and neuropsychological-neurophysiological monitoring. Minim Invasive Neurosurg 50:281-284

25. Raychaudhuri R, Huntington Batjer H, Awad IA (2005) Intracranial cavernous angioma: a practical review of clinical and biological aspects. Surg Neurol 63:319-328

26. Richards S, Aziz N, Bale S, Bick D, Das S, Gastier-Foster J, Grody WW, Hegde M, Lyon E, Spector E, Others (2015) Standards and guidelines for the interpretation of sequence variants: a joint consensus recommendation of the American College of Medical Genetics and Genomics and the Association for Molecular Pathology. Genet Med 17:405

27. Samii M, Eghbal R, Carvalho GA, Matthies C (2001) Surgical management of brainstem cavernomas. J Neurosurg 95:825-832

28. Sanmillan JL, Lopez-Ojeda P, Fernández-Conejero I, FernándezCoello A, Plans G, Ali-Ciurana Y, Gabarrós A (2018) Treatment of cavernous malformations in supratentorial eloquent areas: experience after 10 years of patient-tailored surgical protocol. Acta Neurochir 160:1963-1974

29. Spetzler RF, Martin NA (1986) A proposed grading system for arteriovenous malformations. J Neurosurg 65:476-483

30. Sun G-C, Chen X-L, Zhao Y, Wang F, Song Z-J, Wang Y-B, Wang D, Xu B-N (2011) Intraoperative MRI with integrated functional neuronavigation-guided resection of supratentorial cavernous malformations in eloquent brain areas. J Clin Neurosci 18:1350-1354

31. Taslimi S, Modabbernia A, Amin-Hanjani S, Barker FG 2nd, Macdonald RL (2016) Natural history of cavernous malformation: systematic review and meta-analysis of 25 studies. Neurology 86:1984-1991

32. Turner-Bowker D, Hogue SJ (2014) Short Form 12 Health Survey (SF-12) BT. In: Michalos AC (ed) Encyclopedia of quality of life and well-being research. Springer, Berlin, pp 5954-5957. https:// doi.org/10.1007/978-94-007-0753-5_2698

33. Van Gompel JJ, Marsh WR, Meyer FB, Worrell GA (2010) Patient-assessed satisfaction and outcome after microsurgical resection of cavernomas causing epilepsy. Neurosurg Focus 29:E16

34. Walczak T (1994) Surgical treatment of the epilepsies, ed 2. Edited by Jerome Engel, Jr, New York, Raven Press, 1993, 786 pp, illustrated, \$135.00. Ann Neurol 35:252-252 
35. Wirtz MA, Morfeld M, Glaesmer H, Brähler E (2018) Normierung des SF-12 Version 2.0 zur Messung der gesundheitsbezogenen Lebensqualität in einer deutschen bevölkerungsrepräsentativen Stichprobe. Diagnostica 64:215-226

36. Wostrack M, Shiban E, Harmening K, Obermueller T, Ringel F, Ryang Y-M, Meyer B, Stoffel M (2012) Surgical treatment of symptomatic cerebral cavernous malformations in eloquent brain regions. Acta Neurochir 154:1419-1430

37. Zabramski JM, Wascher TM, Spetzler RF, Johnson B, Golfinos J, Drayer BP, Brown B, Rigamonti D, Brown G (1994) The natural history of familial cavernous malformations: results of an ongoing study. J Neurosurg 80:422-432

38. Zanello M, Meyer B, Still M, Goodden JR, Colle H, Schichor C, Bello L, Wager M, Smits A, Rydenhag B, Tate M, Metellus P, Hamer PDW, Spena G, Capelle L, Mandonnet E, Robles SG, Sarubbo S, Martino González J, Fontaine D, Reyns N, Krieg SM,
Huberfeld G, Wostrack M, Colle D, Robert E, Noens B, Muller P, Yusupov N, Rossi M, Conti Nibali M, Papagno C, Visser V, Baaijen H, Galbarritu L, Chioffi F, Bucheli C, Roux A, Dezamis E, Duffau H, Pallud J (2019) Surgical resection of cavernous angioma located within eloquent brain areas: international survey of the practical management among 19 specialized centers. Seizure 69:31-40

39. Zanello M, Wager M, Corns R, Capelle L, Mandonnet E, Fontaine D, Reyns N, Dezamis E, Matsuda R, Bresson D, Duffau H, Pallud J (2017) Resection of cavernous angioma located in eloquent areas using functional cortical and subcortical mapping under awake conditions. Outcomes in a 50-case multicentre series. Neurochirurgie 63:219-222

Publisher's note Springer Nature remains neutral with regard to jurisdictional claims in published maps and institutional affiliations. 